\title{
KIBS for public needs
}

\section{Dmitri Vinogradov ${ }^{1,2}\left(\mathbb{C} \cdot\right.$ Elena Shadrina $^{2} \cdot$ Marina Doroshenko $^{3}$}

Received: 3 October 2018 / Revised: 22 October 2018 / Accepted: 24 October 2018 /

Published online: 1 November 2018

(c) The Author(s) 2018

\begin{abstract}
Knowledge intensive business services (KIBS) are special in that they rely on knowledge exchange between service providers and consumers and thus intensive cooperation between the two parties is essential at all stages. This implies approaches to find the "right" provider may have to differ from those used in the sector of more homogeneous services and goods. Public procurement regulation aims to improve competitiveness, yet does this help achieving the best value for money in the procurement of KIBS? Legislative constraints on the types of admissible public procurement mechanisms may have an undesirable effect on the provider selection, meaning that services may not be purchased from the most efficient or the most suitable provider. As a benchmark, private consumers are unconstrained in their choice of KIBS providers. We exploit this difference to study the efficiency of KIBS purchases by the public sector, as compared to that in the private sector. Using the 2007 and 2011 waves of a unique survey of KIBS consumers in Russia, we find, inter alia, that the public sector reports lower satisfaction from KIBS and admits a lower level of co-production than the private sector. Our main recommendations refer to the optimal choice of public procurement methods.
\end{abstract}

Keywords Knowledge-intensive business services $\cdot$ Public procurement

JEL classification $\mathrm{H} 57 \cdot \mathrm{L} 84$

Dmitri Vinogradov

Dmitri.Vinogradov@glasgow.ac.uk

Elena Shadrina

evshadrina@hse.ru

Marina Doroshenko

doroshenko@econ.msu.ru

1 University of Glasgow, Glasgow, UK

2 National Research University Higher School of Economics, Moscow, Russia

3 Lomonosov Moscow State University, Moscow, Russia 


\section{Introduction}

Broadly defined, public procurement regulation aims to ensure purchases of goods and services for public needs are "best value for taxpayers' money" (Dimitri 2013), typically by promoting competitiveness of procurement procedures. ${ }^{1}$ Similarly, private businesses aim to ensure investors' money is used most efficiently. The difference is that extant agency problems are significantly constrained by free market forces in the case of the "private business-investor" relationship, and to a large degree unconstrained in the case of the "public body-taxpayer" relationship. As Spagnolo (2012) puts it, public procurement regulation is needed to "keep public buyers accountable in the absence of market pressures"; he also emphasizes rigidities of public procurement rules, particularly with regard to the value of providers' reputation. Reputation is a quality signal, useful when the quality of services or goods mostly depends on their provider. This does not hold for services that are co-produced by and require knowledge exchange between providers and consumers, such as knowledge intensive [business] services (KIBS). In this paper we ask whether public bodies are able to achieve "the best value for money" in this specific sector. In particular, we want to know if competitive procurement procedures are indeed optimal in the notoriously heterogeneous KIBS sector. As a natural benchmark for choices and outcomes we use those reported by private businesses, for which, as highlighted above, market pressures safeguard efficiency. Data comes from a unique survey of KIBS consumers, both public and private, run in Russia in 2007 and 2011.

KIBS are a rapidly developing sector in modern economies. They facilitate innovation processes and foster technological development (see e.g. Antonelli 1998; den Hertog 2000; Haukness 2000; Muller and Zenker 2001; Tether 2003; Koch and Stahlecker 2006; Simmie and Strambach 2006; Link and Swann 2016). In a recent contribution, Iossa et al. (2018) discuss and review relevant literature on public procurement of innovations, however their focus is on types of contracts to be used in innovation procurement, while our emphasis is on the selection of the service provider. One of the key properties of KIBS is customization; the service is tailored to the individual needs of the particular customer and cannot be replicated (see discussion by Tether et al. 2001). This requires a high intensity of co-production (the involvement of customers in the provision of the service, see for example Marion 1997, Spohrer and Maglio 2008). Co-production generates a spillover of knowledge between the service provider and the customer (Doroshenko 2012; Miles 2012). This knowledge transfer distinguishes KIBS from other goods and services, and implies that the use of standard economic mechanisms for the selection of service providers might lead to inefficient outcomes. This is mainly due to the competitive nature of the most commonly used mechanisms, where competition is not well defined for

\footnotetext{
1 This wording is often used by policy-makers and consultants, see, e.g. "The purpose and future direction of public procurement regulation" by S. Bruun-Nielsen, available at http://eupublicprocurement.org. ua/the-purpose-and-future-direction-of-public-procurement-regulation.html?lang=en.
} 
heterogeneous (customized) products. The problem is most evident for public procurement procedures.

The role of public procurement is twofold. First, it is aimed at obtaining goods and services for public needs. Second, government purchases can be used to provide a stimulus via state intervention to support selected economic sectors (and the economy as a whole) through the multiplier effect. ${ }^{2}$ For example, Edler and Georghiou (2007) discuss the stimulating role of public procurement with regard to innovations, and Antonelli (2016) stresses the role of public procurement in the transition to the knowledge economy. This effect, in turn, may be both direct, by purchasing the services from the KIBS sector, and indirect, by demonstrating the benefits of KIBS consumption to the private sector (the indirect effect is discussed in Doroshenko 2012). Typically, private institutions fix small budgets for externally ordered services, but some priority areas may attract preferential public financing, thus becoming more attractive for customers. Science and the research and development of innovations are examples of sectors where public funding can stimulate private demand. In an international context, Uyarra et al. (2014) emphasize that public procurement mechanisms are associated with "the lack of interaction with procuring organizations, the use of over-specified tenders as opposed to outcome based specifications, low competences of procurers and a poor management of risk during the procurement process". These barriers result in the reduced ability of suppliers to innovate, and in less innovative products and services supplied to the public sector.

Previous research has studied the issue of efficiency of public procurement, particularly in the Russian context, from various perspectives. For example, Ivanov (2012) indicates that although auctions are meant to be a competitive (and thus expected to be efficient) method of procurement, they rarely demonstrate price efficiency when used in public procurement in Russia. The author explains this by a high degree of corruption. Yakovlev et al. (2013) indicate numerous provisions in the legislation that allow purchasing authorities to avoid competitive procedures. At the same time, interestingly, they find that the strongest gains from competition in procurement become evident with just 2-3 potential suppliers taking part in the procurement procedures. Balsevich et al. (2012) analyze types of opportunistic behavior in public procurement, in order to explain inefficiencies in the latter. The vast majority of research interprets inefficiencies in procurement in terms of excessively high prices paid or insufficient savings generated by procurement procedures. A notable exception here is Balsevich and Pivovarova (2011) who focus on the degree of informational transparency in public procurement in Russia, which has implications for a broader class of (in-)efficiencies.

In our paper, efficiency is linked to a whole range of (potentially unquantifiable) criteria that underlie the choice of the procurement method. Regulations, such as the UNCITRAL model law, typically understand under the procurement method approaches for the selection of the provider of goods and services, such as open tender, electronic reverse auction, request-for-proposal, framework agreement, or

\footnotetext{
${ }^{2}$ E.g. the government may be interested in supporting domestic producers and thus tends to encourage purchases of goods and services from them.
} 
single-source procurement. In our data, we will be able to know how respondents select their KIBS providers, distinguishing between procurement from a single provider, from a limited number of providers already known to the purchasing body, or from an unconstrained set of potential providers. As there is a correspondence between traditional methods of procurement (as per UNCITRAL) and selection approaches in our data, we also refer to the latter as "procurement methods", in a broad sense. We claim that the choice of this method is crucial for achieving efficiency in the consumption of KIBS purchased, and competitive methods of procurements are not necessarily the first best, at least in the procurement of KIBS. As a benchmark for efficiency, we take the unconstrained choice by freely competitive private businesses, which we then compare with the procurement methods and the resulting levels of efficiency in KIBS purchases of public institutions and government bodies, which are constrained by the procurement legislation.

The paper is organized as follows. Section 2 defines efficiency of KIBS purchases and outlines the theoretical framework that underpins our research question. Section 3 presents our data and explains how it was collected. Section 4 presents the main results with regards to the links between the procurement methods chosen by private and public firms in our data, and respectively levels of customer satisfaction, co-production and absorption of services these firms achieved. Section 5 concludes.

\section{Efficiency of KIBS purchases}

Our main research question is whether public purchases of KIBS offer the best value for money, which seems a natural measure of efficiency in procurement. Measuring efficiency is, however, tricky, as the value of KIBS is highly subjective. On the one hand, a straightforward approach could be to evaluate the reported satisfaction of KIBS consumers, assuming that more satisfaction corresponds to the higher value for money. However, this approach may overestimate efficiency, as customers may be unaware they could potentially achieve an even higher level of satisfaction. On the other hand, value is derived from absorption of services (e.g. Miles 2012), therefore focusing on reported levels of absorption would allow us to alternatively assess efficiency of KIBS purchases. Moreover, KIBS are known to rely on knowledge transfer and to require co-production, both of which ultimately affect the ability of KIBS consumers to absorb services. By considering reported levels of co-production, we can thus complement the above two views (satisfaction and absorption) on efficiency. Similar metrics for private customers of similar KIBS serve as benchmarks for comparison.

We expect a lower efficiency of KIBS in the public sector for the following reasons: (1) legislative restrictions on the procurement methods may adversely affect the choice of suppliers; (2) weaker incentives for the public sector to co-produce effectively; (3) the public sector possessing less experience due to legislative provisions that do not encourage long-term relationships with suppliers (anti-corruption provisions). We will now explore these three points in more detail.

Generally, public procurement is heavily regulated. Regulation aims to improve competitiveness in procurement by ensuring that more potential providers are 
involved in the procurement mechanism, which would lead to purchasing goods and services at lower prices and under better conditions, such as delivery terms. However, competition is associated mainly with highly homogeneous goods and services. For highly customized KIBS, true competition is not really possible due to their heterogeneity, and so a degree of flexibility in choice among various procurement procedures is desirable. This is the reason why we suggest that private business may be more efficient at selecting the best providers of KIBS than the public sector. In particular, we expect private businesses differ from public consumers of KIBS in their choice of procurement methods.

Private businesses also have more incentives to be engaged in effective co-production with KIBS providers, which would ensure proper customization. The government and public institutions are usually non-profit, and numerous studies show internal managerial inefficiencies within them. A review of literature on the advantages of privatized businesses as compared to state-owned ones can be found in Megginson and Netter (2001). In a later work, Bartel and Harrison (2005) explicitly show that, in comparable conditions, the performance of public sector enterprises is below that of their private-sector peers, and privatization is thus deemed to improve performance. We also expect a lower degree and efficiency of co-production from public consumers of KIBS than from private business, due to better incentives and less constraints for private businesses. This implies that the knowledge transfer through co-production would not be so pronounced in the public sector, than in the private one. In this sense, our paper contributes to the old debate on the differences between public and private organizations (see e.g. a seminal review by Rainey et al. 1976; Lan and Rainey 1992, particularly on managers' objectives in public and private enterprises).

Finally, current procurement regulations either explicitly or implicitly forbid long-term customer relationships between procuring bodies and suppliers of goods and services. Although there are usually no direct restrictions on establishing longterm supplier-consumer relationships, legislation requires that standard competitive procedures are used for each contract, thereby making it likely that new contracts would be served by new suppliers. Moreover, legislation including the UNCITRAL Model Law, are very clear about the criteria that can be used to select suppliers, prohibiting preferential treatment of any of them. Establishing a long-term relationship with a supplier is therefore complicated. However, a partnership experience and trust in the particular KIBS provider may contribute significantly to a customer's absorptive capacity. Private businesses face no constraints in this regard, whilst public institutions do, and public institutions would have a poorer experience with KIBS and so be less efficient in KIBS consumption, than private businesses.

\section{Data}

Our study is based on survey data from Russia, which were collected within the annual monitoring of the KIBS sector, since 2007. The monitoring covered ten sectors: advertising, marketing, audit, IT-services, recruitment, engineering, financial advice, legal advice, property development services, and business 
design. This range includes most of the activities described as KIBS in the existing literature (see e.g. Doroshenko et al. 2013 and 2014, for more details). Specialized surveys covered about 600 producers of KIBS annually. Questionnaires included a set of questions that were asked each year and a set of specific questions that were asked only in particular year(s). The surveys were designed as semi-structured interviews with executives who answered questions on their own company and on more general market developments. All surveys were anonymous. Some firms may participate in several surveys (not necessarily successive), but this does not imply generalised results because only $15-20 \%$ of respondents reported that they participated twice.

In 2007 and 2011, parallel surveys covered over 700 business consumers of KIBS. The survey design was similar to KIBS providers one, and the questionnaires were as similar as possible, i.e. they aimed to include the same questions as the questionnaires for providers, for comparability. The 2007 survey also included public sector consumers (214 respondents) who answered the same questions as private firms, and these are the data that we use in this paper. Both business and private consumers were asked about their experiences with all KIBS sectors, and so we obtained over 2000 observations from private customers and over 300 observations from public ones. For the analysis, we used the data from the 2007 survey, as our focus is on the public-versus-private comparison. If examples (of general developments) from other waves of the survey are given, this will be specifically mentioned.

Table 1 reports the scope of the survey in 2007. It was conducted in 13 cities from 9 regions. To obtain a more detailed picture, we divided respondents from the public sector into two groups: government/municipal bodies (149 respondents) and other public sector institutions, like public nurseries, public schools and libraries (65 respondents). For comparison, 781 respondents from the private sector were surveyed.

Table 1 reveals an uneven structure of KIBS purchased by the public sector, with the majority of respondents having experience with advertising. Only a few of them used marketing or property development services. One of the main observations from this data is that the private sector is more homogeneous in terms of their experience with KIBS, whereas the public sector demonstrates excessive concentration in some areas (e.g. advertising and IT) and quite a limited experience with others (e.g. marketing). The data indicate that public sector institutions are more actively consuming KIBS, as compared with government bodies. The most frequently purchased services for both of them have been advertisement and IT. Public sector institutions have more frequently been provided with audit $(38.5 \%$ against $10.1 \%$ for government bodies), engineering (36.9\% a gains $19.5 \%$ ) and financial services (30.8\% against $13.4 \%)$.

Table 2 shows the percentages of respondents in the public sector that reported having purchased KIBS (respondents from the private sector were not asked this question). Although it is theoretically possible that some services are used without being actually purchased (e.g. sponsorship, donorship or access to the service that had been purchased by a different institutional structure, which is possible in the public sector), a comparison of Tables 1 and 2 reveals that the amounts of purchases and amounts of usage are highly correlated. This allows us to relate the usage-related 


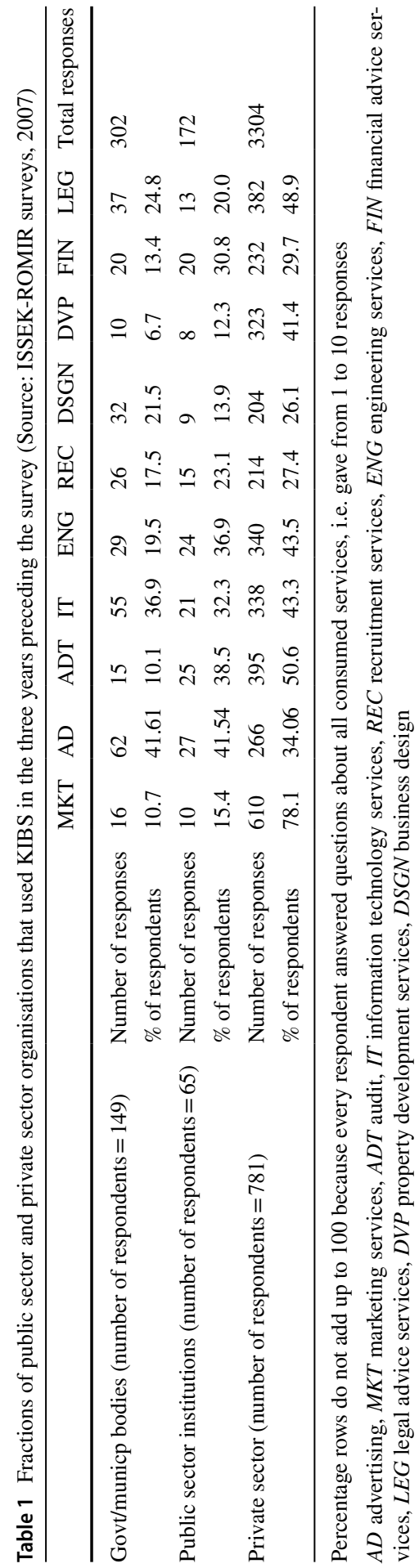


Table 2 Types of KIBS purchased by the public sector (Source: ISSEK-ROMIR surveys, 2007)

\begin{tabular}{|c|c|c|c|c|c|c|c|c|c|c|c|}
\hline & \multirow[t]{2}{*}{ Avg } & \multicolumn{10}{|c|}{ Sectors } \\
\hline & & MKT & $\mathrm{AD}$ & ADT & IT & ENG & REC & DSGN & DVP & FIN & LEG \\
\hline Government bodies & 20.2 & 10.7 & 41.6 & 10.1 & 36.9 & 19.5 & 17.4 & 21.5 & 6.7 & 13.4 & 24.8 \\
\hline Public institutions & 26.2 & 12.3 & 41.5 & 38.5 & 32.3 & 36.9 & 23.1 & 13.9 & 12.3 & 30.8 & 20.0 \\
\hline
\end{tabular}

Percentage rows do not add up to 100 because each respondent answered questions about all consumed services, i.e. gave from 1 to 10 responses

$A D$ advertising, $M K T$ marketing services, $A D T$ audit, $I T$ information technology services, $R E C$ recruitment services, $E N G$ engineering services, FIN financial advice services, $L E G$ legal advice services, $D V P$ property development services, $D S G N$ business design, Avg average across all responses

features (like levels of satisfaction or absorption of services) to the method of procurement used.

On average, in 2007 in each of the 10 KIBS sectors, $70 \%$ of respondents from government bodies reported expenditures on KIBS under $1 \mathrm{~m}$ roubles (appr. $£ 20,000$ at the time of the survey), whereas $9 \%$ of them spent between $1 \mathrm{~m}$ and $5 \mathrm{~m}$ roubles (appr. $£ 20,000-£ 100,000$ ). For public institutions, these figures were $59 \%$ and $18 \%$, respectively, whereas for the private sector they were noticeably lower; $44 \%$ of respondents reported expenditures under 500,000 roubles $(£ 10,000)$ and $16 \%$ expenditures between 500,000 and 1mRUR ( $£ 10,000-20,000)$. The private sector is therefore more likely to spend large amounts on KIBS purchases (40\% against $21-23 \%$ in the public sector).

In the observed period, public procurement in Russia was regulated by the Federal Law No. 94-FZ "On placing orders to supply goods, perform work or provide services for state and municipal needs", of 21 July 2005, which limited purchasing mechanisms to mainly tenders and auctions. These provisions were not unique to Russia, although the UNCITRAL Model Law on Public Procurement suggested a variety of methods which all aimed to promote competition and transparency of procurement procedures (see UNCITRAL 2011), and they created obstacles for the proper selection of KIBS providers. In particular, $57 \%$ of public institutions reported that they were not satisfied with their providers, where $40 \%$ of providers reported losses from projects with public customers.

To judge on the method of procurement chosen, we use respondents' answers to the question "How do you select providers of KIBS when purchasing their services?", where they were given the following options "We usually work with 1-2 reliable suppliers", "We choose from offers of 3-5 firms with good reputation", "Tendering, including firms we don't know yet", or "None of the above". We note that these answers can be associated with traditional labels for procurement methods such as single-source procurement, requests of quotations, and open tenders, respectively. With this wording of the question and the answer options, we cannot distinguish, for example, between auctions and open tenders, however our primary focus is on the number of participants in each selection procedure, hence available data is fit for purpose. The range of options were elaborated and validated during structured personal interviews with industry experts. This was because the original 
survey mainly addressed private businesses, which also explains the relatively small sample of public sector enterprises. In this sense, the answers to the question show which approaches out of those commonly used in the private sector are also popular in the public sector. The number of "None of the above/not sure" responses is almost negligible. From this, we may conclude that the question itself was comfortable for respondents, and the list of procurement methods, whilst not exhaustive from the regulatory or theoretical point of view, still encompasses the vast majority of approaches with which respondents can identify themselves.

Among the main reasons for dissatisfaction, an average of $60 \%$ of public institutions referred to missed deadlines, and $76 \%$ were unable to absorb the service properly. The latter figure potentially indicates insufficient co-production between public customers and KIBS providers, and the lack of proper knowledge transfer. On the one hand, legislative restrictions forbid any pre-contracting communication between the tenderer and its potential providers, though our analysis proves that it is exactly at this stage that the need for co-production is the greatest. On the other hand, public bodies have insufficient incentives for proper co-production, given that understaffing is a common problem, and purchases of services are typically considered as full outsourcing. Below we focus on these issues in more detail.

Our main variables - satisfaction, absorption and co-production -come from consumers' responses to the corresponding survey questions. Satisfaction is measured on a 5-point scale from answers to the question "Please, assess on a five-point scale, the degree to which your company is satisfied with the services you were provided, with $1=$ not satisfied at all, and $5=$ fully satisfied." No further clarifications of "satisfaction" were given to respondents, leaving the interpretation of the term up to them. Yet, in pilots and feedback respondents reported no difficulty in this, suggesting satisfaction is a well understood concept.

We complement this rather broad measure of the value derived from the service, by looking at the degree of the service absorption, derived from answers to the question "To which degree have you applied/implemented/used the results of the services you were provided in [the given KIBS area]?". Respondents could choose one of the following four options (or give no response): (1) the results were not used, (2) results were partly (to some extend) used/applied/implemented, (3) results were mainly, although not completely, applied/implemented/used, and (4) results were applied/implemented/used in full.

Finally, we look at the level of co-production in KIBS. Respondents asked the following question: "To which degree is your company, as a customer, involved in the process of the production ${ }^{3}$ of services you rendered". Respondents were asked to use a 10-point scale, where 1 corresponds to "careful explanation of what is needed, and then no involvement at all until the work is done" and 10 corresponds to "full involvement, continuous interaction, joint realization of the project". Providing these detailed descriptions of the options on the scale ensures respondents understand the question and the meaning of "co-production".

\footnotetext{
3 In Russian, the word "realization" instead of "production" was used. In English-speaking literature the "production of services" is a more common term (e.g. Kelley et al. 1990).
} 


\section{Results}

Our most important and surprising result is that the most popular procurement method, also in the private sector, is single-source procurement. The highest level of satisfaction is also achieved when the single-source procurement is chosen. The lowest level of satisfaction is achieved when procurement is implemented through tender procedures. After discussing the methods of procurement and the levels of satisfaction, we complement the analysis in subsections 4.3 and 4.4 by focusing on co-production and absorption of KIBS.

\subsection{Procurement methods}

The main difference between purchases of KIBS in the private and public sectors is the method of procurement. The private sector is free of any constraints either on the choice of service provider or on the selection criteria. The public sector complies with legislation that determines feasible procurement methods and specifies the selection criteria. This is a reason to analyze the degree of satisfaction from KIBS consumption, bearing in mind the selection approaches. The main procurement methods are (1) tendering, (2) request for quotations, (3) request of proposals, (4) negotiations, (5) electronic reverse auctions, and (6) single-source procurement (see, e.g. UNCITRAL 2011).

The methods of procurement as reported by the respondents are shown in Tables 3, 4 and 5 .

While single-source procurement is the most popular method for acquiring KIBS, strikingly, the private sector on average used single source procurement less frequently than public organizations (differences significant ${ }^{4}$ at least $\mathrm{p}<0.05$ level). There are two possible explanations for this. The first one underlies public procurement legislation, where corruption potentially drives public entities to use undesirable and inefficient methods of procurement (see, e.g. Castro et al. (2018) and references therein for a discussion of corruption in public procurement.) The second one is suggested in this paper: existing legislative constraints and prescriptions on various forms of procurement do not leave enough space for their effective practical application. We prove that it is flexibility which makes tenders attractive to private businesses, while rigidities make this procedure inappropriate for KIBS procurement by the public sector. UNCITRAL (2011) promotes the flexibility of procurement procedures, particularly in tendering. EBRD (2011) indicated the rigidity of Russian procurement legislation at the time. We show that, in that period, tendering for KIBS actually generated lower customer satisfaction in the public sector, which was incompatible with the corruption view on the choice of procurement methods. Excessively constrained tendering was therefore indeed a less efficient mechanism than single-source procurement.

\footnotetext{
${ }^{4}$ Where not reported otherwise, two-sided t-tests for differences in means were used.
} 


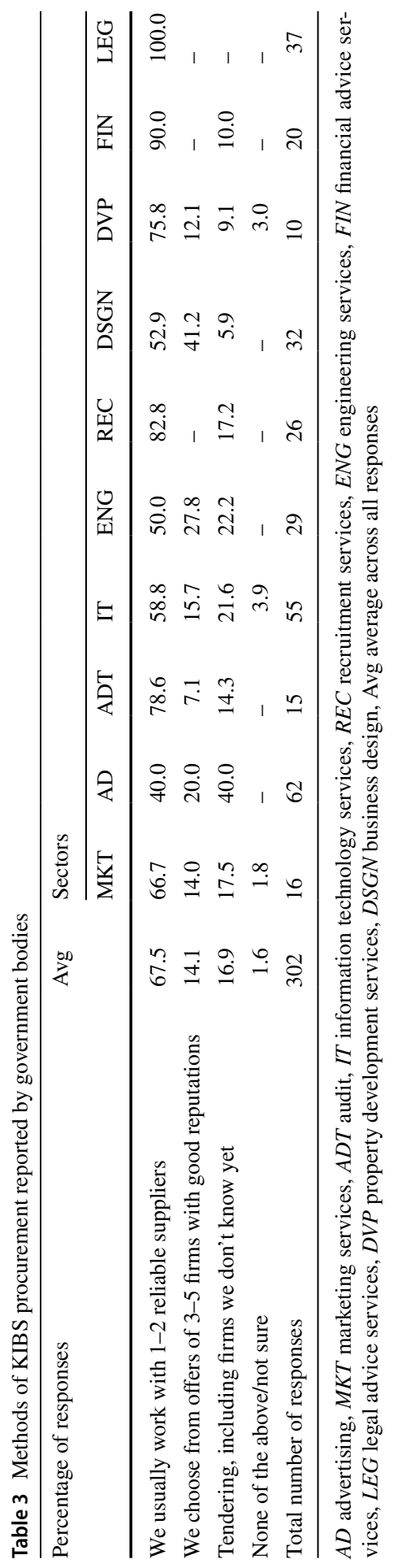




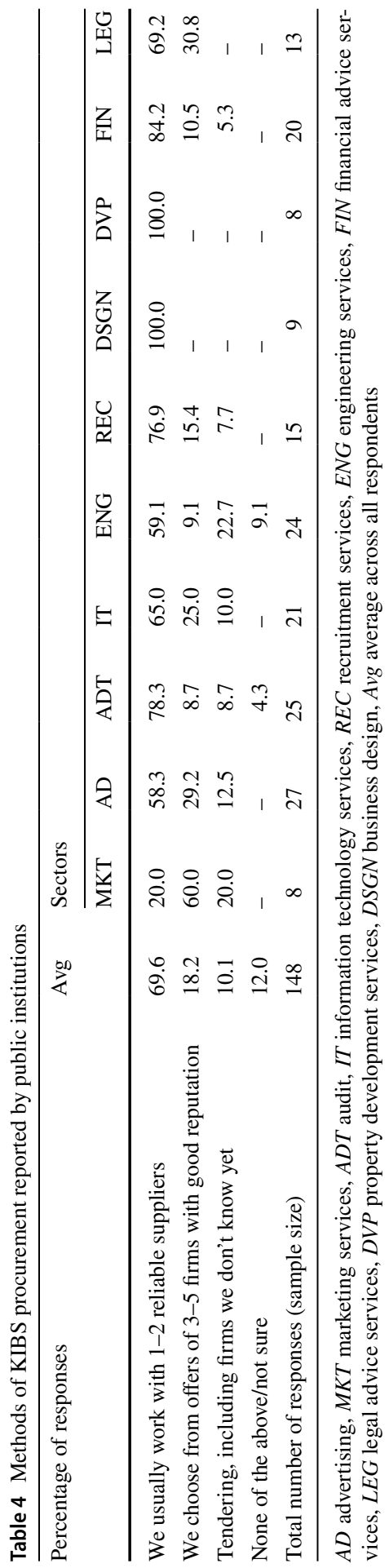




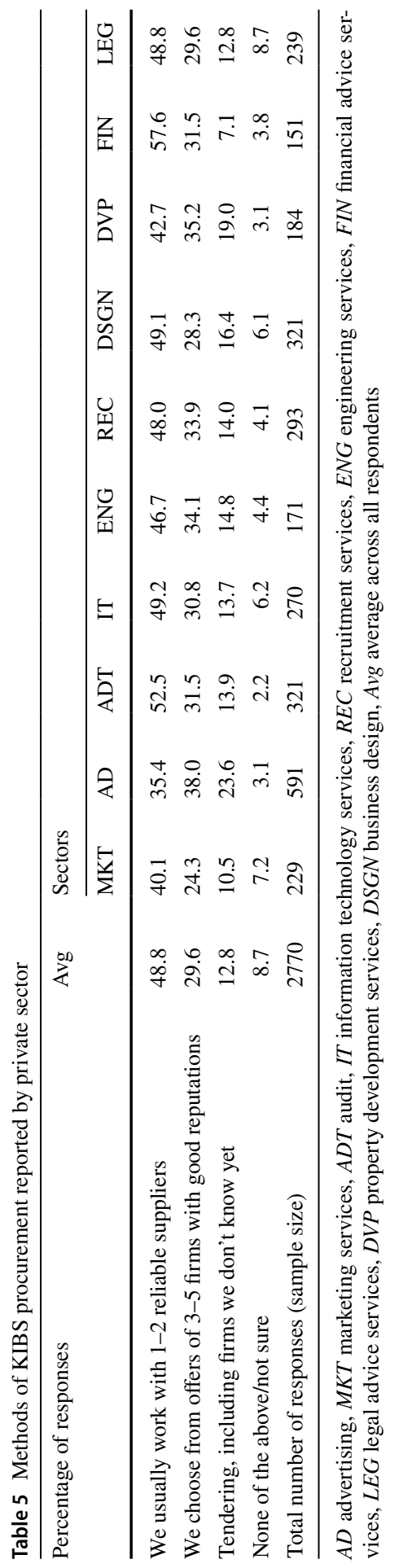


a

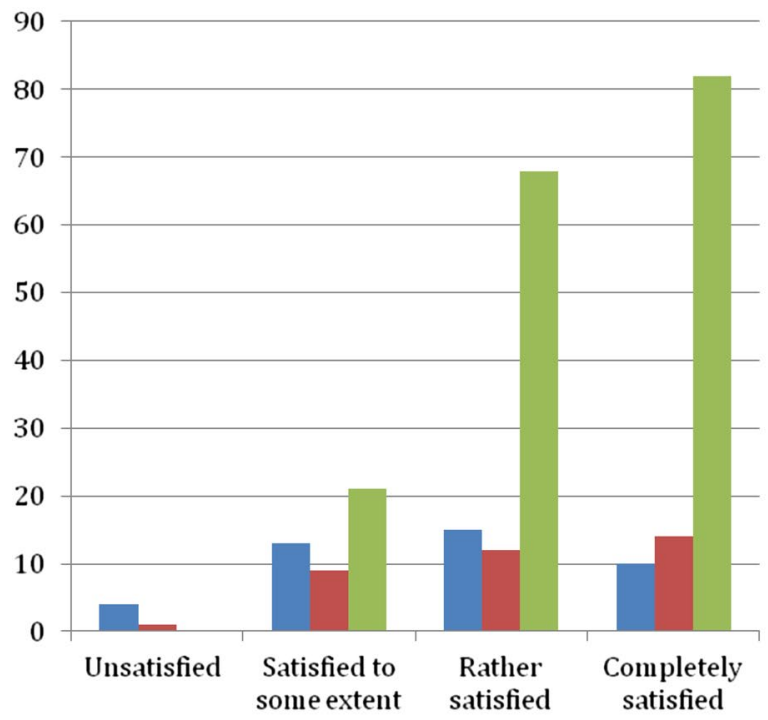

- Tendering, allowing from unknown companies

Choosing from 3-5 companies with good reputation

Working with 1-2 reliable suppliers

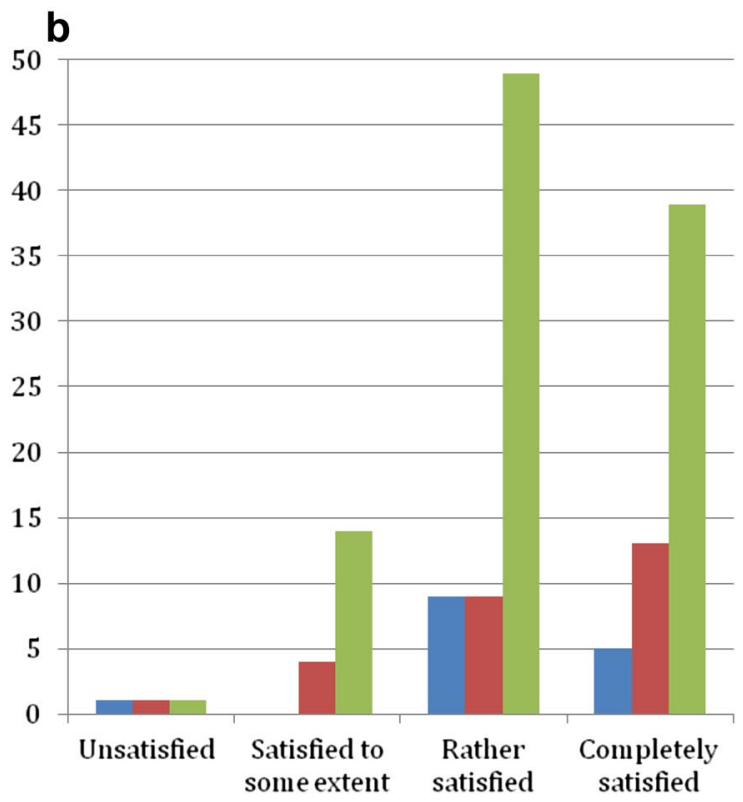

Tendering, allowing from unknown companies

Choosing from 3-5 companies with good reputation

-Working with 1-2 reliable suppliers

Fig. 1 a Joint distribution of responses to the questions "How do you purchase KIBS?" and "Estimate the level of your satisfaction with rendered KIBS ": government bodies. b Joint distribution of answers to the questions "How do you purchase KIBS" and "Estimate the level of your satisfaction with rendered KIBS “: public institutions 


\subsection{Customer satisfaction}

The relationship between the method of procurement and the level of satisfaction (as reported by the respondents) is not straightforward (see Fig. 1a for government bodies and Fig. 1b for public institutions). Both figures highlight that the number of highly satisfied customers remarkably increases when moving from tenders towards single source procurement, whereas dissatisfaction increases in the opposite direction. The majority of customers in the public sector achieve the highest level of satisfaction when KIBS are purchased from 1 to 2 reliable suppliers.

It should be emphasized here that public procurement legislation encourages neither long-term relationships with suppliers, nor purchasing from a limited number of suppliers. A certain discrepancy therefore arises between the legislative objective and its actual effects; the number of absolutely satisfied respondents is relatively low for those who use tender procedures $(23.8 \%$ in the private and $33.3 \%$ in the public sector). The share of satisfied private sector respondents who use single source procurement is almost twice as high: $47.9 \%$ reported absolute satisfaction. Therefore, we can observe the advantages of the single source procurement in the free business environment, while in the public sector. The share of complete satisfaction from the single source procurement remains low (37.8\%). The public sector derives the highest level of satisfaction (48.1\%) from requests of quotations from 3 to 5 suppliers with good reputations (compared with $38.9 \%$ in private sector). Both public and private sectors prefer to work with a limited number of KIBS suppliers, yet the amount of completely satisfied respondents in the public sector is remarkably smaller. From this, public procurement is rather less efficient, if satisfaction represents value for money.

Respondents were also asked about the criteria that they use when they choose service suppliers. ${ }^{5}$ For government bodies, the most important criteria are the timeline of the service delivery (24.5\% of responses), quality $(23 \%)$ and the supplier's experience $(11.9 \%)$. The least important criterion is the supplier's membership in professional associations. For public institutions, the results are similar: quality $(24.9 \%)$, the timeline of service provision $(18.8 \%)$ and experience $(11.1 \%)$ are the most important, whereas membership in associations is not important at all. Other factors like the price of services, qualification of the service provider, personal contacts and advice of peers are of medium importance (see Tables 6 and 7).

A comparison of Tables 6 and 7 shows that the quality of the service is the prime criterion for the private sector, while government bodies are mostly focused on the timeline of the service delivery (the difference between average popularity of the first and the second criterion is significant at $\mathrm{p}<0.05$ for the private sector, insignificant for the public sector). A possible explanation is that private sector businesses are results-oriented, and they are prepared to wait longer for the sake of perfect

\footnotetext{
5 Similar, although partly differently worded, criteria are used by Gronroos (1988) as factors of good perceived service quality: (1) professionalism and skills, (2) friendly attitudes and behavior, (3) access and flexibility, (4) reliability and trustworthiness, (5) recovery, i.e. availability of an immediate corrective action if anything goes wrong, and (6) reputation and credibility.
} 


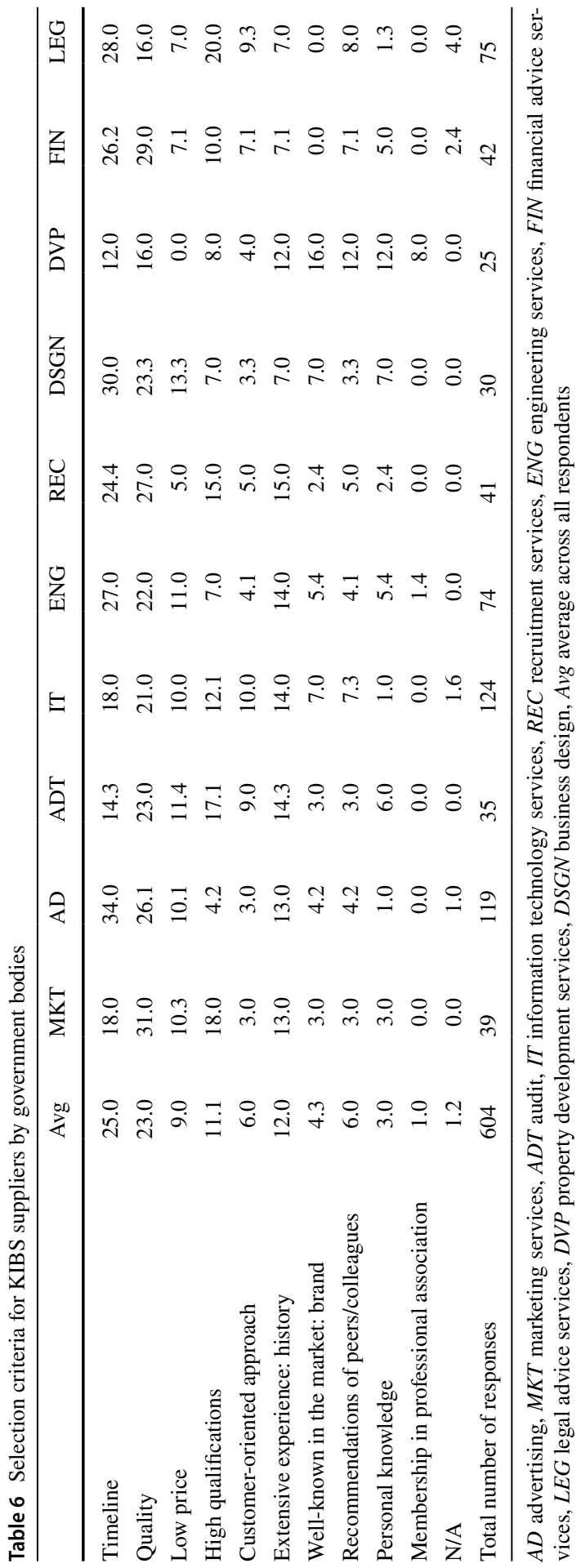




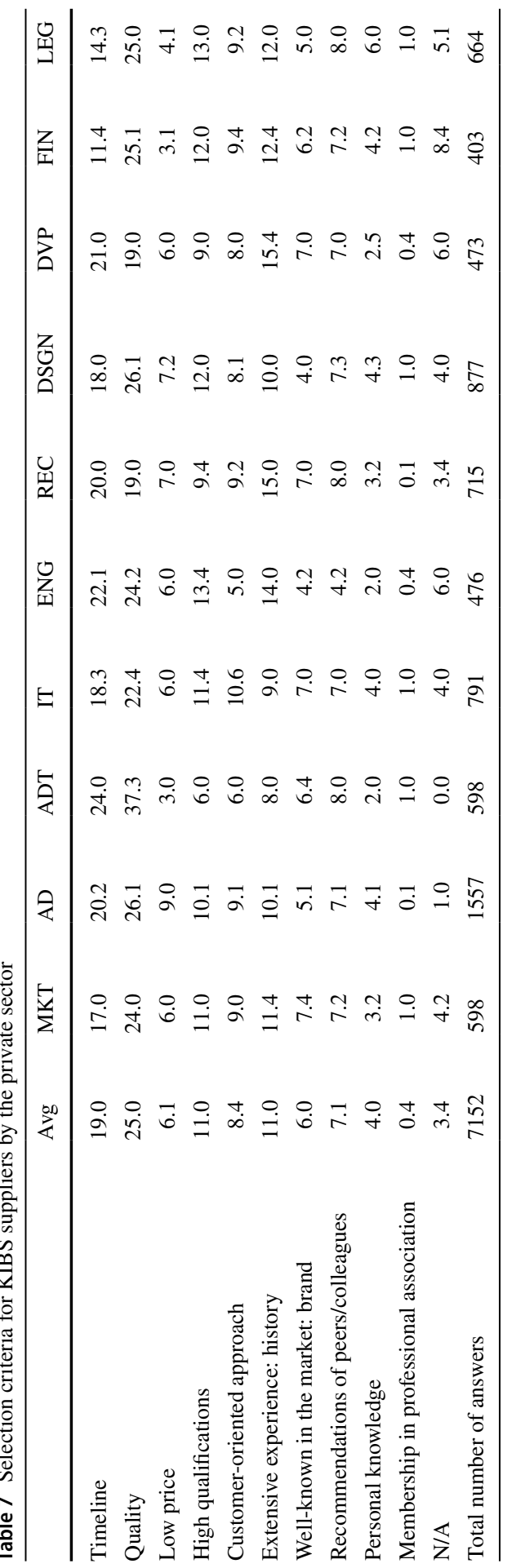


quality. For government bodies, reportability is more important, therefore rendering the timeframe of service delivery one of the key selection criteria.

Another observation from Tables 6 to 7 is that both the private sector and government bodies indicate the qualifications of the supplier's personnel as a selection criterion more frequently than the low price (difference in the average percentage of responses between the two criteria is significant at $\mathrm{p}<0.01$ ). This effect might be insignificant due to the limited number of observations, yet it is worth mentioning. For the remainder of criteria, we do not observe any remarkable differences.

At the time of the survey, the procurement legislation in Russia established four main criteria for the public purchases of services: (1) price; (2) quality and qualification (a single criterion); (3) timeline for delivery, and (4) conditions and warranties. In many cases, the desired quality of KIBS cannot be formally and completely described in a call for offers (notification of contract, or invitation to tender). An important reason is that the ultimate quality of the rendered service crucially depends on the level of co-production and on the knowledge transfer between the consuming body and its supplier at the initial phase of the project (setting up the terms of reference). However, the legislation prohibits any communication between the parties once the call for offers has been published. As a result, the public sector does not have another option but to use suppliers' qualifications as the best available proxies for the quality of their future services. Conversely, the private sector enjoys the flexibility of communications with potential suppliers when negotiating the contract, when the proper specifications of the desired quality of KIBS are determined. As a result, the quality requirements (this is the most important factor for the private sector) are fixed in the contract; the qualifications of the service provider do not particularly matter, and the price factor becomes more important.

The low priority of customer-centricity in the public sector is also in line with our general point that consumers from the private sector have better incentives (and flexibility) to be engaged in efficient co-production with service suppliers. The availability of supplier's help and advice during and after the service provision is an important factor for general satisfaction. Again, a formal description of the "customer-oriented approach" in a public call for offers is hardly possible, while "market history" is a measurable criterion, which therefore gains higher importance for KIBS consumers from the public sector.

\subsection{Co-production}

KIBS production is hardly efficient without close cooperation between suppliers and their customers. The nature of KIBS implies the need in a specific knowledge about the particular customer rather than common knowledge about a generalised consumer. A knowledge-intensive service therefore has two producers instead of one: a company who renders the service (it supplies its intellectual resources, mainly qualified labour), and a company who orders a service (it supplies its information resources, i.e. knowledge about itself). This process is called external resource incorporation or co-production. 


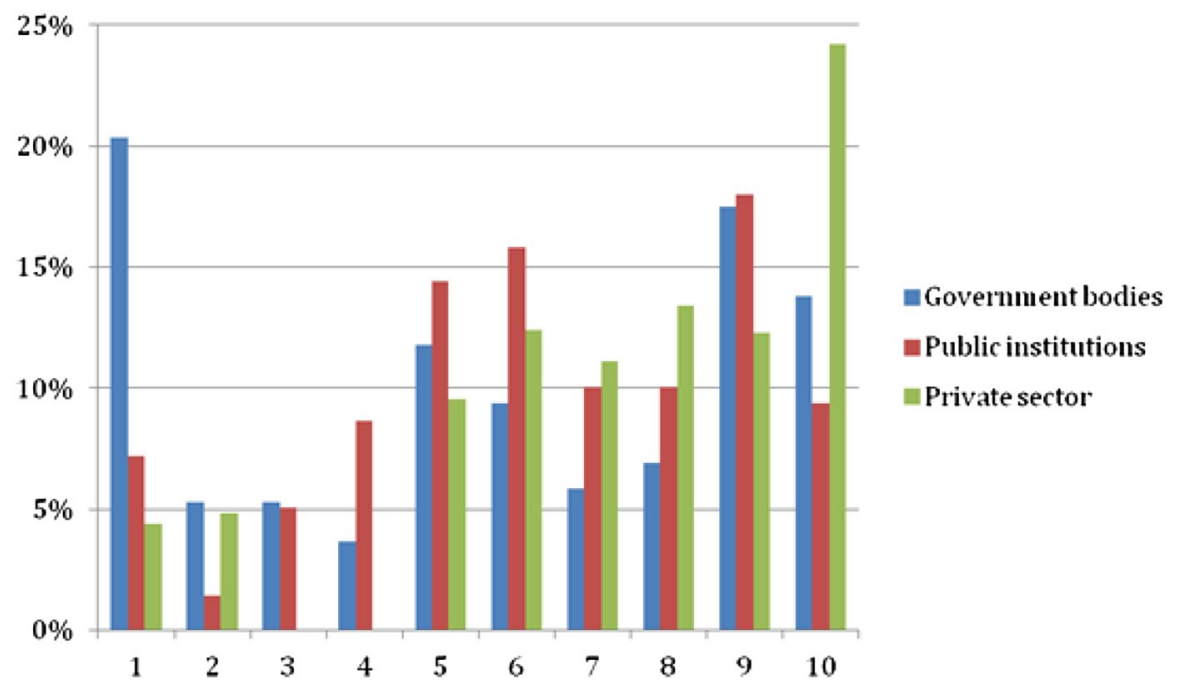

Fig. 2 Levels of co-production (horizontally) as estimated by KIBS consumers (average percentage over all reported sectors, vertically)

Our survey shows that $33.3 \%$ of government bodies and $20.9 \%$ of public institutions estimate their involvement in co-production as low (score 1-4 on a 10-point scale), while $42.7 \%$ of government bodies and $45.9 \%$ of public institution estimated it as high (scores 7-10 on the 10-point scale). Although we observe gaps between the perceptions of public institutions and government bodies, the one on the upper part of the scale is not significant. A more crucial difference arises between public customers as a whole and private KIBS users. Only $15.9 \%$ of consumers from the private sector estimate their co-production as low and $57.5 \%$ attribute it a score between 7 and 10 (see Fig. 2 for details). This difference between private and public sectors $^{6}$ supports our hypothesis about stronger incentives for the private sector to co-produce KIBS.

The levels of co-production vary between sectors. Though this paper does not aim to perform a thorough cross-section analysis, some differences are notable. Advertising, for example, shows little difference between public and private sectors (24-52\% of respondents give their engagement co-production the highest scores of 7-10). In engineering, the share of high scores in the public sector reaches $72.6 \%$, against $48.6 \%$ in the private sector. Similarly, in property development, the share of intensive co-producers in the public sector is larger than in the private one $(53.6 \%$ against 49.4\%), although the difference is not significant. In design, government bodies report high co-production more frequently than the private sector $(63.6 \%$ against 59.6\%) while public institutions do so less frequently (56.8\%). Again, the gap may seem insignificant, but this example reemphasizes the differences between

\footnotetext{
${ }^{6}$ Differences between distributions of responses of government bodies and private firms are significant at $\mathrm{p}<0.01$ (Kolmogorov-Smirnov test).
} 


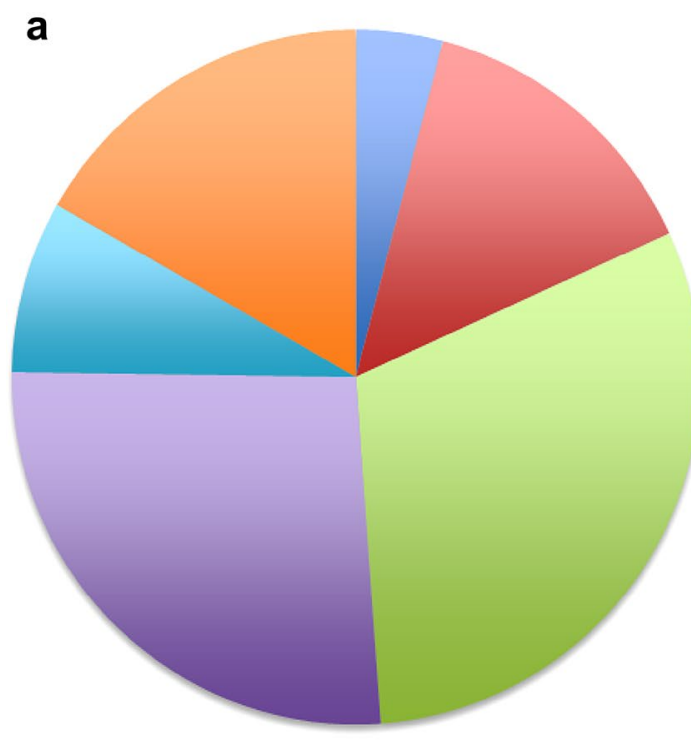

b

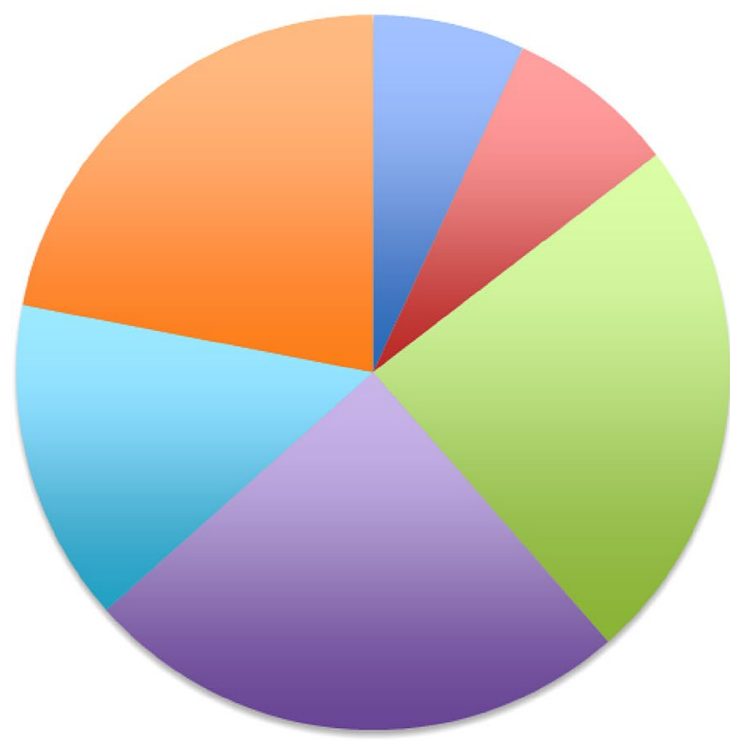

- We do not understand what co-production the service provider needs

$\square$ We understand the need for co-production, but we refuse to participate it

- Our staff has no time to spare beyond their principal duties

- We do not want to participate in for this service

We have insufficient capacities for

no answer

- Customers are unable to co-produce

\section{a Customers do not understand what co- production we need \\ Customers understand what we need from co- production, but they refuse to participate \\ a Customers do not want to co-produce because they pay for the service \\ Customers have no time to spare beyond their principal duties}

Fig. 3 a Reasons for insufficient co-production (ISSEK-ROMIR survey of private KIBS consumers, 2011). b Reasons for insufficient co-production (ISSEK-ROMIR survey of KIBS providers, 2011)

government bodies and public institutions taken together and the private sector. This issue requires more detailed investigation in a separate study.

The 2007 survey did not address the question of the reasons for insufficient customer co-production with public bodies, yet a subsequent survey in 2011 

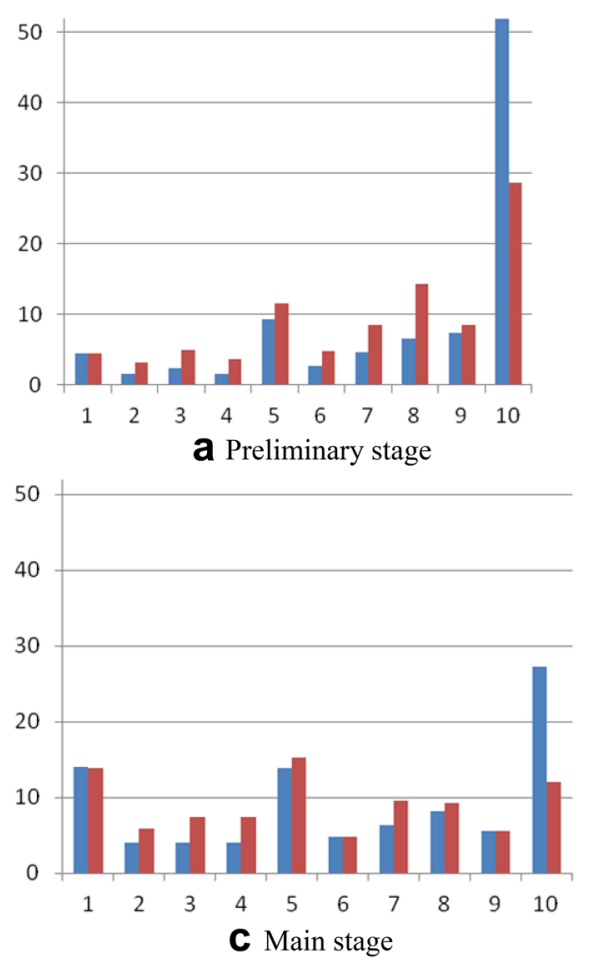
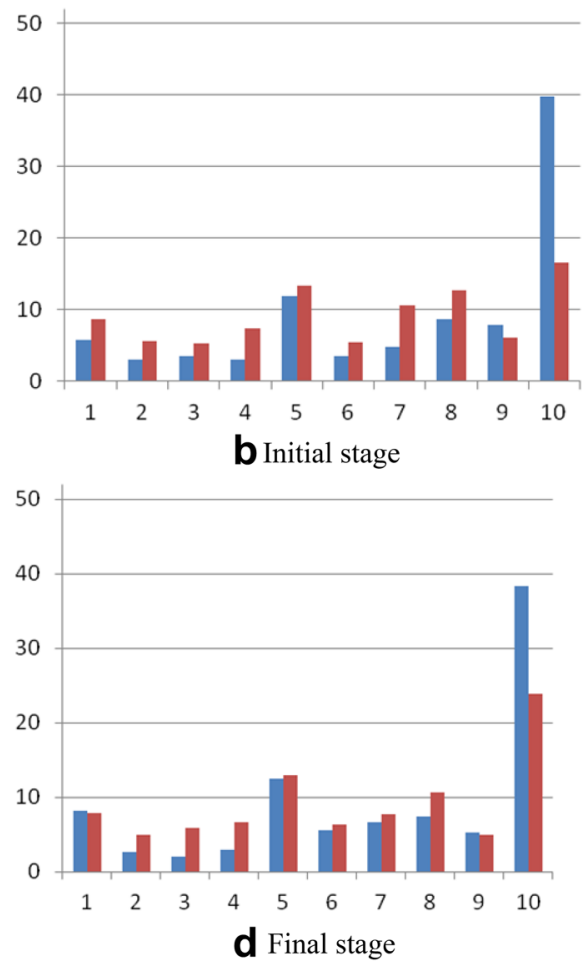

Fig. 4 Required (blue) and actual (red) levels of co-production (on a scale from 1 to 10 , $x$-axis, lowest co-production on the left, highest to the right; percentage of responses on the $y$-axis); ISSEK-ROMIR survey of KIBS suppliers, 2011) (color figure online)

posed this question to business customers. The main reasons in the private sector are shortages of resources (the staff does not have enough time for extra duties, $30.6 \%$ of respondents) and a negative attitude towards co-production ("we are paying for the service and it's the service provider who should work", 26.4\%)— see Fig. 3a for details.

A slightly different picture is given by service providers (Fig. 3b), who answered the same question about the reasons for insufficient co-production, using the same 10-point scale. Importantly, we did not ask them to distinguish between public and private sectors, i.e. they gave only general estimates. The view of KIBS providers (on customers in general) differs from that of private customers. Providers noticeably mention customers' resistance to co-production, whereas sector customers more frequently argue that their staff has no time to participate in co-production. These differences may be explained by a difference in perception, yet an important point is that providers' experience covers customers from the public sector as well. If this asymmetry can, at least partially, be explained by the attitude of public sector managers, then we would expect a higher resistance to co-produce in the public sector, as well as a more pronounced 
role of other factors which prevent efficient co-production. On this point, an interesting observation has been documented by Lan and Rainey (1992) who stress that managers in the public sector are more likely to stick to the rules and formal job descriptions. This suggests that a more formalistic approach in the public sector may be deemed responsible for a lower level of co-production. Generally, this is consistent with our observations on the reasons for poor co-production in the public sector.

Co-production varies at different stages of the project's implementation. We distinguish between four stages: preliminary (before the start of the project, e.g. clarifications of the terms of references), initial (the preparation and the start of the project), main (the actual production of the service) and final (completion, final adjustment of the project's results to the client's needs and clarification of the remaining issues and the final report) stages of the KIBS provision. Figure 4 compares two profiles of co-production: the one that KIBS suppliers need for proper service provision (required, or desired, co-production) and the one they perceive as actually achieved with their customers (actual co-production). Note that the desired level of co-production on average exceeds the actual one at all four stages, although the distribution of responses is rather flat. Importantly, at all four stages, the number of suppliers who require highest co-production (at level 10) is about twice as high as the number of those who actually report this high level of co-production. A strong need for co-production at the preliminary stage (preparation of the terms of reference) changes by lower co-production at the initial and in the main stages, and then by the new increase of co-production at the final stage of the project. Figure 4 depicts visible changes in the distributions of answers. The distribution in the preliminary phase noticeably shifts towards lower scores compared with other panels, and the distribution at the main stage is closer to uniform than any other. The distributions at the beginning and final stages are quite similar to each other. Significantly, it is the preliminary stage that requires (and involves) the most intensive coproduction (the vast majority of respondents gave scores of 5 and above).

The typical public procurement legislation forbids interactions between a public body and the potential supplier of services at the preliminary stage of procurement procedures. This norm hinders co-production at a very important stage, when the parameters of the demanded service should be specified during close interactions between consumers and suppliers. Further on, co-production at later stages may require adjustments and amendments of the initial terms of reference, when customers achieve a better understanding of their needs after benefiting from the knowledge transfer from KIBS suppliers (see Doroshenko 2012). Any changes in contracts are usually prohibited by public procurement legislations. Regulatory constraints therefore put obstacles in the way of proper co-production and thus hinder proper satisfaction from KIBS in the public sector.

Table 8 presents the joint distribution of co-production and satisfaction. ${ }^{7}$ Responses from the private sector are concentrated around high co-production and high satisfaction. This can be viewed as a proxy for the first-best outcome, because

\footnotetext{
7 Each cell gives the percentage of respondents that gave the corresponding combination of answers.
} 


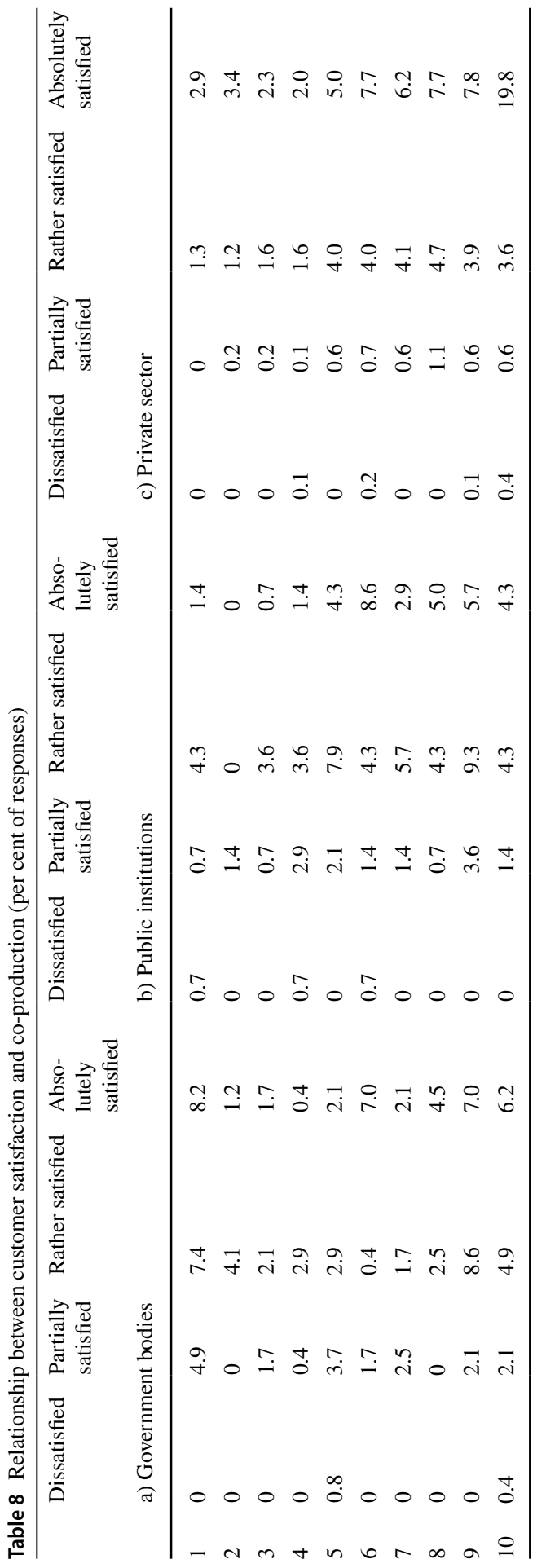


private firms are unconstrained in their choice of the level of co-production, in comparison to the public sector. The latter, however, demonstrates noticeable differences. As discussed above, government bodies are highly constrained by the law in their ability to coproduce, which is reflected in the distribution of their answers, demonstrating roughly equal likelihoods of low and high co-production. Less constrained public sector institutions show higher levels of co-production. It is difficult to judge based on the link between co-production and satisfaction, although the unconstrained choice of private firms indirectly suggests that higher satisfaction may be achieved through better co-production.

On the one hand, co-production does not appear to contribute much to the ultimate satisfaction of government bodies and public institutions from the services rendered. On the other hand, co-production is indispensable for the provision of highly customized KIBS (see, e.g. Bettencourt et al. 2002). This suggests that public procurement of KIBS lacks customization. Indeed, existing restrictions on qualitative choice criteria and the emphasized role of formalized parameters of public purchases all prohibited communications with potential service providers before the start of procurement procedure. The rigidity of the contract in terms of ongoing changes might lead to a high degree of standardization of services. These standard services do not require high levels of co-production. As a result, if the customer prefers standard services, high satisfaction may be achieved even if co-production is low.

\subsection{Absorption of services}

The absorption of KIBS is another important indicator of procurement efficiency. Indeed, the service cannot be fully absorbed if it does not perfectly match the needs of the customer. Our data do not reveal any significant difference between service absorption in public and private sectors in general, though the levels of absorption of different KIBS vary. 73\% of the government bodies report full absorption of KIBS, and $18 \%$ reported that services are mostly absorbed. Public institutions reported $79 \%$ and $16.2 \%$, respectively, while the private sector reported $78.9 \%$ and $10.8 \%$, respectively. ${ }^{8}$ These results seem to contradict our previous findings about the relationship between co-production and satisfaction. If higher co-production leads to better satisfaction, and if satisfied customers are more likeliy to absorb services in full, then the public sector should be less likely to report full absorbtion of KIBS, which contradicts the aforementioned observations. To explain this puzzle, we turn to the suppliers' data.

Suppliers of KIBS believe that only $68.2 \%$ of their KIBS are fully absorbed, and $14.2 \%$ are absorbed partially. This asymmetry of perception on the levels of absorption between service providers and their customers provides a key to the puzzle. Suppliers have perfect information about the properties of their KIBS and on the efforts that the customer should undertake in order to use the service properly. Even

${ }^{8}$ Differences between government bodies and private firms are significant at least at $\mathrm{p}<0.05$. 
Table 9 Relationship between service absorption and the method of procurement (per cent of responses)

\begin{tabular}{lllrrrrrrrrrr}
\hline Method & \multicolumn{2}{l}{ Degree of absorption (from low to high) } \\
\cline { 2 - 13 } & \multicolumn{1}{l}{ a) Government bodies } & \multicolumn{1}{l}{ b) Public institutions } & \multicolumn{3}{c}{ c) Private sector } \\
\hline $1-2$ & 1.3 & 0.8 & 11.7 & 56.1 & 0.7 & 2.1 & 7.1 & 61.4 & 0.8 & 1.6 & 3.2 & 43.6 \\
$3-5$ & 0 & 0.4 & 2.9 & 12.1 & 1.4 & 0.7 & 2.1 & 14.3 & 0.1 & 1.3 & 2.6 & 11.7 \\
Tender & 0.4 & 0.4 & 5.0 & 8.8 & 0 & 0 & 3.6 & 6.4 & 0.2 & 1.3 & 5.2 & 28.4 \\
\hline
\end{tabular}

if the customer firm might seem to know its ability to absorb the service better than the supplier does, it is however the supplier who can find the untapped potential of the delivered service. This overestimation of the degree of absorption is observed both in the public and private sectors. Despite this, we argue that co-production helps private enterprises to provide a more accurate estimate.

Co-production helps consumers improve their understanding of their own needs. Consider a customer with strong incentives to co-produce; their initial knowledge about the rendered service often changes during co-production, e.g. the customer may discover unexpected benefits from service consumption, along with understanding that not all service qualities are easily absorbed (they might require additional training of staff, or even organizational changes). The perceived level of absorption reported by this customer will then be high compared to initial expectations, though imperfect in comparison with the new deeper knowledge that was obtained through co-production.

On the contrary, a customer with weak incentives for co-production acquires less new knowledge, and therefore their understanding of benefits from co-production does not differ much from initial expectations. If the final service design is similar to the one initially commissioned, then a high level of absorption is most likely to be reported because the customer was prepared to absorb exactly what was initially rendered. In other words, the perceived level of absorption crucially depends on the customer's grasp of this service, which, in turn, depends on co-production. ${ }^{9}$

Do chosen methods of procurement affect absorption? Table 9 shows that the absorptive capacity of KIBS consumers is highly sensitive to procurement methods. Similarly to satisfaction, the highest reported absorption is associated with singlesource procurement in the public sector, whereas the private sector demonstrates a substantially larger share of consumers who are able to achieve the highest level of absorption after an open, flexible tender.

\footnotetext{
9 Alternatively, an abnormally high (as compared to satisfaction) level of service absorption in the public sector can be explained by a tendency of public bodies to render more standardized KIBS, which are also easier to absorb. As discussed above, this is due to the regulatory requirements to publish full specifications of the items (services) to be purchased, prior to the start of the procurement procedure. The issue of standardization is not the focus of the current paper, but this argument is in line with the main finding, which is that it is a lack of flexibility in the procurement regulation that lowers efficiency in the consumption of KIBS by the public sector.
} 


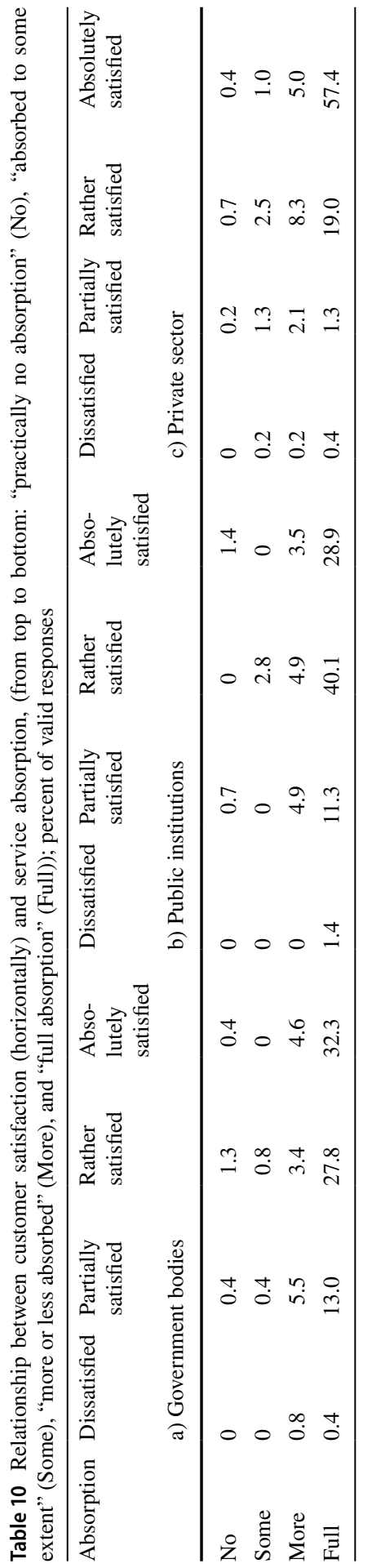


We can interpret the matrices in Table 9 as joint probability distributions for procurement methods and levels of absorption. This view suggests that if government bodies use single-source procurement or offers from a limited number of suppliers, the probability of achieving the highest level of absorption is almost $80 \%$, while if they announce a tender, the probability decreases to $60 \%$. For public institutions, the respective probabilities are $86 \%$ in case of a single-source procurement, $76 \%$ for offers from 3 to 5 suppliers, and $64 \%$ for a tender. The private sector exhibits the highest probabilities of achieving a perfect absorption of KIBS (89\% for single-source procurement, $75 \%$ for offers from 3 to 5 suppliers, and $81 \%$ for tenders.) If we focus on tenders only, the private sector demonstrates a notably higher probability of perfect absorption than the public sector. In the public sector, the more competitive the procurement procedure, the lower the chance for perfect absorption.

Is there any relationship between absorption and satisfaction? One way to look at it is through the joint distribution of responses, as in Table 10, from which we can derive conditional probabilities of achieving a particular level of satisfaction, given the level of absorption. In both the public and the private sectors, we observe that the likelihood of absolute satisfaction increases with the degree of absorption: for example, among those government bodies who report some absorption none report absolute satisfaction (the majority, two-thirds, report "rather satisfied"), while the fraction of absolutely satisfied grows to $32.17 \%$ among those who report absorption to a larger degree, and further to 43.95\% among those who report full absorption (precise definitions and gradations are in Sect. 3). Similarly, among public institutions who report absorption to a large degree, the likelihood of being absolutely satisfied is $26.32 \%$, growing to $35.37 \%$ among those who report full absorption. The relationship seems to be stronger in the private sector: $20 \%$ of those who report "some" absorption also report absolute satisfaction, growing to $32.05 \%$ of those who report large degrees of absorption and to $73.5 \%$ among those who report full absorption. Looking at the two highest levels of satisfaction together, delivers the probability of being fully or rather satisfied, given the full absorption of services, $98 \%$ in the private sector vs. $83-84 \%$ in public sector.

The results are surprising. Full absorption of KIBS in the private sector almost automatically means absolute or close to that satisfaction, while in the public sector appropriation and satisfaction hardly correlate at all; for over $15 \%$ of those who report full absorption, a fully absorbed service is associated with dissatisfaction. Our discussion above suggests the puzzle appears due to mechanisms of procurement. Recall from Fig. 1a, b that the proper choice of the procurement procedure (the single-source procurement that does not break the law) provides an $87 \%$ probability of satisfaction in the public sector. If a procuring body has to use a different method of procurement, it can absorb the service in full, but given the limitations of the procurement method, this service does not perfectly match the needs of the customer, which is reflected in a lower satisfaction. 


\section{Conclusions}

Although public purchases of KIBS could, in general, be efficient, they face a number of obstacles. In this paper, we focused on the methods of procurement and legislative constraints as potential sources of inefficiency. Our surveys covered public institutions and government bodies which faced the above constraints, and private firms, who we use as an "unconstrained optimum" benchmark. The data suggests that single-source procurement is the best choice in the unconstrained case: it is the most frequently used by private businesses and it maximizes the probability of achieving the highest satisfaction. Despite regulatory constraints, it is also the most popular procurement method in the public sector. However, even tendering ensures a much higher probability of satisfaction in the private sector than in the public one. This can be explained by the limited range of permitted selection criteria for tenders in the public sector, which were imposed by procurement legislation at the time of the survey. Importantly, this legislation stipulated that price should always be used as one of the criteria, and its weight among other criteria may be as high as $80 \%$. In our data, price, however, is not the dominating factor for public bodies in procurement procedures. This exemplifies the sort of efficiency-reducing constraints that we address in this paper. In order to change the situation, it is important to allow for more flexibility in the public procurement of KIBS, to relax restrictions on tenders and competitions, and to reduce the weight of price in the selection criteria.

Our results also highlight that the choice of the procurement method might matter for consumers' satisfaction and the absorption of services. The flexibility in procurement which the private sector enjoys, ensures a better choice of the service provider, better co-production at the preliminary negotiations stage, and the ability to make changes in contract specifications at later stages of the project's implementation, if co-production reveals the need for them. On the contrary, the public sector operates under restrictions, which often forbid communication between the purchasing entity and the supplier of services, require a fixed set of service specifications to be identified and announced before the procurement procedure, and discourage long-term customer relationships. In our view, it is these restrictions that force public sector consumers to prefer single-source procurement as the best option to achieve high satisfaction and the absorption of services (recall, this is the preferred option in the private sector as well). This is intuitively in line with suggestion that previous experience with a particular provider not only signals the quality of this provider's services, but is also beneficial in terms of knowledge that the provider has already gained about this particular customer.

Alongside this, for the private sector we observe that tenders may be at least as efficient as single source procurement. This is particularly important if a new service is being rendered, with no previous experience with any of the potential providers (also, possibly, in innovation procurement as in Iossa et al. 2018). For the public sector we observe the worst satisfaction from KIBS ordered through tenders (as compared to other procurement methods). This emphasizes the impact of regulatory restrictions faced by the public sector. If the legislation aims to 
improve efficiency (increasing satisfaction and absorption of services), it should allow for greater flexibility in public procurement.

Some of these issues are already addressed under the UNCITRAL Model Law (UNCITRAL 2011). Our analysis suggests that its provisions, particularly the flexibility of choice in procurement methods, should resolve some of the problems mentioned in this paper, although this deserves a further investigation in a separate paper. However, we should recognize that with regulated purchases of KIBS, an attempt to promote competitive procurement may force public sector entities to render standardized services that do not perfectly match their needs. A full and exhaustive specification of the service is not feasible at the preliminary stage without consulting potential suppliers, and changes in specifications at later stages may result in greater efficiency rather than in corruption. It is also important to recognize that long-term relationships improve the efficiency of KIBS production, due to better knowledge of the particular customer.

Finally, it is widely accepted that managerial incentives in the public and private sectors differ. Our findings nevertheless indicate that there are important distinctions within the public sector itself, i.e. between government bodies and other public institutions (public nurseries, public schools, libraries, etc.). The latter differ from the private sector much less than the former, especially in terms of co-production. However, our survey samples were limited, and so these results require further testing.

Acknowledgements Financial support from the Government of the Russian Federation, within the framework of the Basic Research Program at the National Research University Higher School of Economics, and through the implementation of the 5-100 Programme Roadmap from the National Research University Higher School of Economics, is acknowledged. This work has been funded by the Russian Academic Excellence Project "5-100". Vinogradov and Shadrina also acknowledge support from the Russian Foundation for Basic Research: RFBR Grant No. 18-010-01166.

Open Access This article is distributed under the terms of the Creative Commons Attribution 4.0 International License (http://creativecommons.org/licenses/by/4.0/), which permits unrestricted use, distribution, and reproduction in any medium, provided you give appropriate credit to the original author(s) and the source, provide a link to the Creative Commons license, and indicate if changes were made.

\section{References}

Antonelli, C. (1998). Localised technological change, new information technology and the knowledge and the knowledge-based economy: The European evidence. Journal of Evolutionary Economics, 8, 177-198.

Antonelli, C. (2016). The bumpy ride to the knowledge economy. Economia e Politica Industriale Journal of Industrial and Business Economics, 43(3), 337-344.

Balsevich, A., Pivovarova, S., \& Podkolzina E. (2011). Information transparency of public procurement in Russian regions: Estimation and explanations, National Research University-Higher School of Economics, WP BRP Series 01/2011

Bartel, A., \& Harrison, A. (2005). Ownership versus environment: Disentangling the sources of public-sector inefficiency. Review of Economics and Statistics, 87(1), 135-147.

Bettencourt, L. A., Ostrom, A. L., Brown, S. W., \& Roundtree, R. T. (2002). Client coproduction in knowledge-intensive business services. California Management Review, 44(4), 100-128.

Castro, M. F., Guccio, C., Pignataro, G., \& Rizzo, I. (2018). Is competition able to counteract the inefficiency of corruption? The case of Italian public works, in S. Saussier and P. Valbonesi (eds.) "New Theoretical and Empirical Developments," the Intesa Sanpaolo Special Issue on Public Procurement. Economia e Politica Industriale - Journal of Industrial and Business Economics, 45(1), 55-84. 
den Hertog, P. (2000). Knowledge intensive business services as co-producers of innovation. International Journal of Innovation Management, 4(4), 491-528.

Dimitri, N. (2013). "Best value for money" in procurement. Journal of Public Procurement, 13(2), 149-175.

Doroshenko, M. (2012). How knowledge intensive business services upgrade their customers: Evidence from Russia. In E. D. Maria, R. Grandinetti, \& B. D. Bernardo (Eds.), Exploring knowledge-intensive business services: Knowledge management strategies (pp. 79-99). UK: Palgrave Macmillan.

Doroshenko M. E., Miles I., \& Vinogradov D. (2013). Knowledge intensive business services as generators of innovations. Working papers by NRU Higher School of Economics. Series WP BRP "Science, Technology and Innovation". 2013 No. 12.

Doroshenko, M., Miles, I., \& Vinogradov, D. (2014). Knowledge intensive business services: The Russian experience. Foresight-Russia, 8(4), 24-39.

EBRD. (2011). "Public procurement assessment: Review of law and practice in the EBRD region," European Bank for Reconstruction and Development.

Edler, J., \& Georghiou, L. (2007). Public procurement and innovation: Resurrecting the demand side. Research Policy, 36, 949-963.

Gronroos, C. (1988). Service quality: The six criteria of good perceived service. Review of Business, 9(3), $10-13$.

Hauknes, J. (2000). Dynamic innovation systems: What is the role of services? In M. Boden \& I. Miles (Eds.), Services and the knowledge-based economy. London: Continuum.

Iossa, E., Biagi, F., \& Valbonesi, P. (2018). Pre-commercial procurement, procurement of innovative solutions and innovation partnerships in the EU: Rationale and strategy. Economics of Innovation and New Technology, 27(8), 730-749.

Ivanov, A. (2012). Why the Russian federation public procurement market does not turn into the market for lemons. NACC J Special Issue, 5(2), 37-51.

Kelley, S. W., Donnelly, J. H., Jr., \& Skinner, S. J. (1990). Customer participation in service production and delivery. Journal of Retailing, 66(3), 315.

Koch, A., \& Stahlecker, T. (2006). Regional innovation systems and foundation of knowledge intensive business services. European Planning Studies, 14(2), 123-146.

Lan, Z., \& Rainey, H. G. (1992). Goals, rules, and effectiveness in public, private, and hybrid organizations: More evidence on frequent assertions about differences. Journal of Public Administration Research and Theory, 2(1), 5-28.

Link, A. N., \& Swann, C. A. (2016). R\&D as an investment in knowledge based capital. Economia e Politica Industriale Journal of Industrial and Business Economics, 43(1), 11-24.

Marion, F. (1997). Service coproduction and customer participation. In H. Mühlbacher \& J.-P. Flipo (Eds.), Advances in services marketing (pp. 17-26). Wiesbaden: Gabler-Verlag.

Megginson, W., \& Netter, J. (2001). From state to market: A survey of empirical studies on privatization. Journal of Economic Literature, 39, 321-389.

Miles, I. (2012). KIBS and knowledge dynamics in client-supplier interaction. In E. Di Maria, R. Grandinetti, \& B. Di Bernardo (Eds.), Exploring knowledge-intensive business services, knowledge management strategies. London: Palgrave.

Muller, E., \& Zenker, A. (2001). Business services as actors of knowledge transformation: The role of KIBS in regional and national innovation systems. Research Policy, 30(9), 1501-1516.

Rainey, H. G., Backoff, R. W., \& Levine, C. H. (1976). Comparing public and private organizations. Public Administration Review, 36(2), 233-244.

Simmie, J., \& Strambach, S. (2006). The contribution of KIBS to innovation in cities: An evolutionary and institutional perspective. Journal of Knowledge Management, 10(5), 26-40.

Spohrer, J., \& Maglio, P. P. (2008). The emergence of service science: Toward systematic service innovations to accelerate co-creation of value. Production and Operations Management, 17(3), 1-9.

Tether, B. S. (2003). The sources and aims of innovation in services: Variety between and within sectors. Economics of Innovation and New Technology, 12(6), 481-505.

Tether, B. S., Hipp, C., \& Miles, I. (2001). Standardisation and particularisation in services: Evidence from Germany. Research Policy, 30, 1115-1138.

UNCITRAL. (2011). Model law on public procurement. Vienna: United Nations Commission on International Trade Law.

Uyarra, E., Edler, J., Garcia-Estevez, J., Georghiou, L., \& Yeow, J. (2014). Barriers to innovation through public procurement: A supplier perspective. Technovation, 34(10), 631-645. 
Yakovlev, A., Bashina, A., \& Demidova, O. (2013). Efficiency of simple homogeneous good procurement under rigid governmental regulation: The case of sugar sand procurement in Russia. Ekonomicheskii zhurnal VSE, 2013, 617-645.

Balsevich A., Yeremina A., Zoroastrova, I., Morozov, I., Ostrovnaya, M., Pivovarova, S., \& Podkolzina, E. (2012). Vozmozhnosti gorizonatlnoy I vertikalnoy integrarsii pri osushestvlenii gosudarsyvennyh zakupok: analiz situatsiy/Perspectives for vertical and horizontal integration in public procurement: Case analysis. Working papers by NRU Higher School of Economics WP10/2012/01 (in Russian). 